\title{
Remediation of Heavy Metal (Cd, Cr, Cu, Co, and Ni) Ions from Kaolinite Clay Using Molecular Micelles Chelators and D-Optimum Experimental Design
}

\author{
Sayo O. Fakayode*, Ashley M. Taylor, Maya McCoy, Sri Lanka Owen, Whitney E. Stapleton, \\ Carmen Grady, David A. Pollard \\ Department of Chemistry, Winston-Salem State University, Winston-Salem, USA. \\ Email: *fakayodesa@wssu.edu \\ Received May $24^{\text {th }}, 2013$; revised June $28^{\text {th }}, 2013$; accepted July $5^{\text {th }}, 2013$ \\ Copyright (C) 2013 Sayo O. Fakayode et al. This is an open access article distributed under the Creative Commons Attribution Li- \\ cense, which permits unrestricted use, distribution, and reproduction in any medium, provided the original work is properly cited.
}

\begin{abstract}
This study investigated the potential utility of poly (sodium $N$-undecanoyl-L-leucyl-valinate) (poly-L-SULV), poly (sodium $N$-undecanoyl-L-leucyl-alanate) (poly-L-SULA), and poly (sodium $N$-undecanoyl-glycinate) (poly-SUG) molecular micelles (MMs) as chelators for heavy metal $(\mathrm{Cd}, \mathrm{Cr}, \mathrm{Cu}, \mathrm{Co}$, and $\mathrm{Ni}$ ) ion remediation of kaolinite clay using D-optimum experimental design. D-optimum experimental design was employed to simultaneously investigate the influence of design variables such as the buffer $\mathrm{pH}$, chelator concentration, and centrifuge speed to evaluate the optimum conditions and to reduce the time and cost of metal ion remediation. The partition coefficients of the metal ion concentrations between the kaolinite clay and chelator equilibrium were also evaluated. In addition, the influence of metal ion concentrations on the remediation capability of the chelators was evaluated by conducting remediation studies at four different (10 ppm, $40 \mathrm{ppm}, 60 \mathrm{ppm}$, and $80 \mathrm{ppm})$ metal ion concentrations. In general, the results of the remediation efficiency and partition coefficients obtained in this study are highly metal ion dependent and also dependent upon the chelator used for the remediation. Specifically, the remediation efficiency of the molecular micelles was found to be comparable to or better than the corresponding remediation efficiency obtained when SDS or EDTA was used for the remediation. However, at optimum conditions, poly-SULV and poly-L-SULA molecular micelle chelators demonstrated superior remediation efficiencies for $\mathrm{Cr}$, with remediation efficiency of $99.9 \pm 8.7 \%$ and $99.1 \pm 0.7 \%$, respectively.
\end{abstract}

Keywords: Heavy Metal Ion Remediation; Molecular Micelles Chelator; D-Optimum Experimental Design; Kaolinite Clay

\section{Introduction}

The development of efficient and environmentally friendly chelating agents for potential remediation of heavy metal ions (HMIs) [1-8] from contaminated soils continues to be of active environmental research study. In general, soil HMI remediation strategies often involve the immobilization, desorption, removal, or extraction of HMIs from the contaminated soil. The use of several extracting agents and chelators including surfactants, phosphoric acids, sulphate, polyvinyl alcohol, EDTA, diethylenetriaminepentaacetic acid, and humic materials has been strategically employed for metal ion remediation in various environmental studies [9-14]. The poten-

${ }^{*}$ Corresponding author. tial utility of biomass and various plant materials for biosorption and bioremediation of heavy metals from polluted soils has also been investigated [15-17]. Many studies have primarily focused on the removal of a single metal ion; however, others studies have investigated competitive and simultaneous desorption of several metal ions from soil. Undoubtedly, most of the previous metal ion remediation techniques and chelators have proven useful and efficient for the remediation of some metal ions. For example, phosphoric acid, SDS and EDTA are commercially available at affordable prices and are nontoxic, with high remediation efficacy. However, some currently available chelators have inherent short-comings including, poor selectivity, and poor solubility in aqueous and organic solvents, limiting their practical application 
for metal ion remediation. In addition, some metal ion chelators are relatively dangerous to handle and may not be environmentally friendly. Besides the shortcomings of the metal ion chelators, most of the previously reported metal ion remediation studies have often involved the investigation of one experimental variable at a time, resulting in many experiments, lengthy analysis time, and high cost of analysis.

In this study, we hypothesized that poly (sodium $\mathrm{N}-\mathrm{u}$ ndecanoyl-L-leucyl-valinate) (poly-L-SULV), poly (sodium $N$-undecanoyl-L-leucyl-alanate) (poly-L-SULA), and poly (sodium $N$-undecanoyl-glycinate) (poly-SUG) molecular micelles (MMs) can be utilized as chelators for simultaneous $\mathrm{HMI}(\mathrm{Cd}, \mathrm{Cr}, \mathrm{Cu}, \mathrm{Co}$, and $\mathrm{Ni})$ remediation from kaolinite clay. We also proposed that, a modern D-optimum experimental design can be used to simultaneously optimize and investigate experimental conditions such as, the buffer $\mathrm{pH}$, chelator concentration, and centrifuge speed to achieve the global optimum extraction conditions for metal ion remediation from kaolinite clay. The MMs used in this study were made from amino acids, the building blocks of proteins, hence, are non toxic and are more environmentally friendly. In addition, MMs have high solubility both in the aqueous and organic solvents, further increasing their practical application for metal ion remediation of diverse environmental sample matrixes. Additionally, compared with monomeric surfactants, MMs have no critical micelle concentration; therefore, MMs can be used across a wider concentration range. Furthermore, MMs are polymers of enhanced stability and large surface areas with potential strong binding sites for metal ions. Moreover, the amine head groups of MMs can be readily modified and tailored to achieve metal ion remediation selectivity. Besides, the use of D-optimum experimental design strategy used in this study is preferable to the traditional analysis of one variable at a time because the number and order of experiments to be conducted is known in advance [18-22]. Also, only a few experiments are required to establish the optimum heavy metal ion condition using D-optimum experimental design, ultimately reducing both the time and cost of analysis. We have previously demonstrated advantages of modern experimental design over traditional analysis of one variable at a time in chromatographic separation $[22,23]$ and in nanoparticle synthesis [24]. Studies from other laboratories have also showed the benefits of modern experimental design strategies over the analysis of one variable at a time $[19-22,25,26]$.

\section{Materials and Methods}

\subsection{Chemicals and Materials}

A commercial kaolinite clay, sodium phosphate dibasic, sodium phosphate monobasic, tris (hydroxymethyl) aminomethane (tris), sodium tetraborate decahydrate (borate), analytical grade metal free nitric acid (99.999\%) and Whatman (ashless) filter paper were purchased from Sigma-Aldrich. $\mathrm{Cd}, \mathrm{Cr}, \mathrm{Cu}, \mathrm{Co}$, and $\mathrm{Ni}$ standards and centrifuge tubes were purchased from Fisher Scientific. The chemical structures of the MMs chelators used for the metal ions remediation are shown in Figure 1. A detailed synthetic procedure for the MMs has been previously reported elsewhere $[27,28]$.

\subsection{AAS Instrumentation and Heavy Metal Analysis}

Heavy metal analysis was performed using a flame atomic absorption spectrophotometer (Shimadzu, AA6300) using a pre-mixed burner air-acetylene flame. The flow rates of the fuel and oxidant gas were always carefully optimized for each metal analysis. Other routine instrumental checks and calibrations were always performed on the spectrometer before use to ensure the accuracy, reliability, and performance of the spectrometer.

\subsection{D-Optimum Experimental Design}

The initial metal ion remediation study involved the screening of experimental factors including, the amount of kaolinite clay required to ensure complete adsorption and binding of the metal ions. In addition, the time to achieve complete binding of metal ions on kaolinite clay and the orbital shaker speed were investigated. Once the amount of kaolinite clay, the time taken for complete adsorption of metal ions, and the speed of orbital shaker were established, the chelator concentration, the buffer $\mathrm{pH}$, and centrifuge speed were then optimized to achieve optimum remediation of metal ions from kaolinite using D-optimum experimental design. The chelator concentration, buffer $\mathrm{pH}$, and centrifuge speed were investigated at three levels. The buffer $\mathrm{pH}$ was investigated at acidic ( $\mathrm{pH}$ 5.5), physiological ( $\mathrm{pH}$ 7.4), and basic conditions $(\mathrm{pH} 10.0)$ to simulate the typical soil $\mathrm{pH}$ ranges. The chelator concentration was investigated at low $(0.1$ $\% \mathrm{w} / \mathrm{v})$, medium $(0.5 \% \mathrm{w} / \mathrm{v}$, and high concentration $(1.0$ $\% \mathrm{w} / \mathrm{v})$. Additionally, the centrifuge speed was investigated at low (2000 rpm), medium (4000 rpm) and high (6000 rpm) speeds. The D-optimum design resulted in a total of sixteen experimental runs performed for each chelator under different experimental conditions (Table 1). The D-optimum experimental design and data analysis was performed using chemometric software (The Unscrambler, CAMO Inc., 9.6). Detailed statistical and mathematical procedure for the D-optimum experimental design is beyond the scope of this study and interested readers may find the design method in various books and 


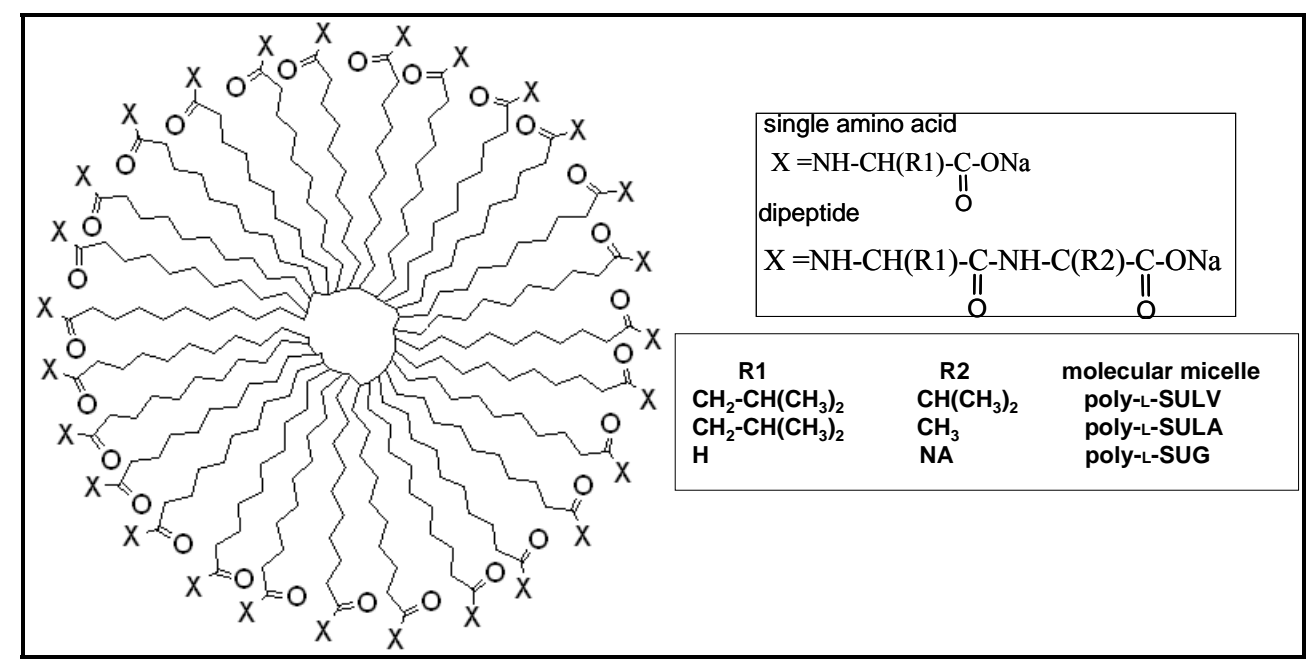

(a)

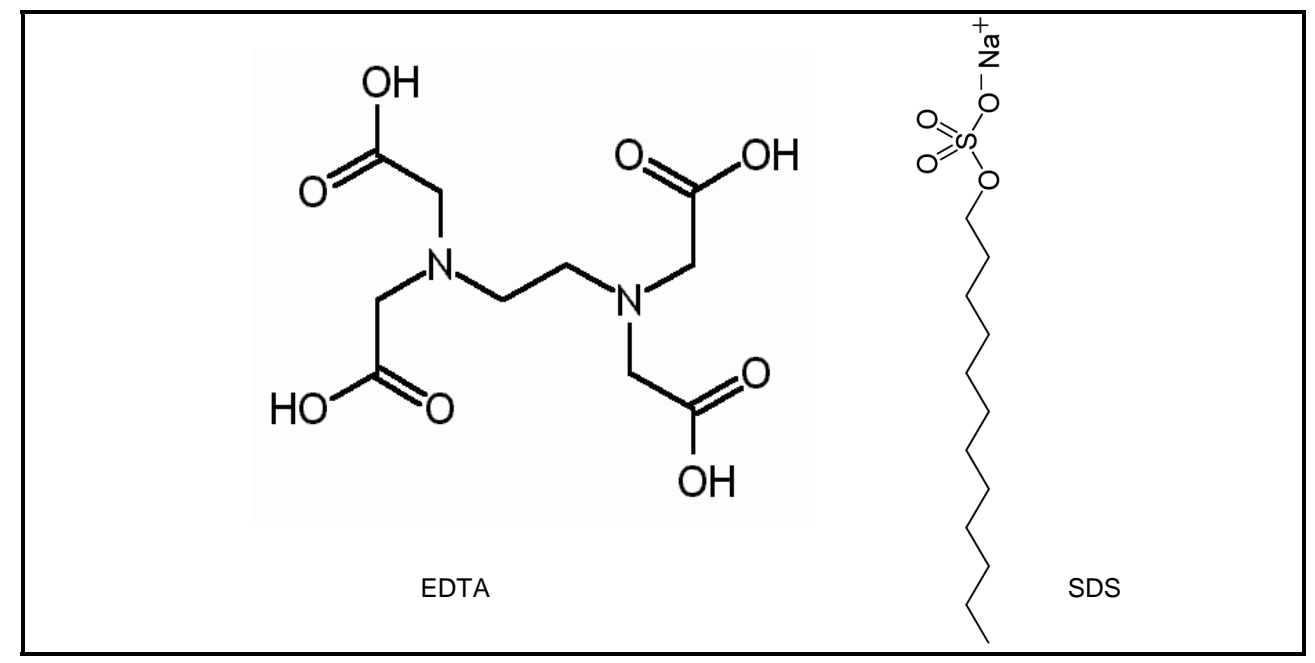

Figure 1. Structure of: (a) Molecular micelles; (b) Conventional chelators EDTA and SDS.

monographs [18].

\subsection{Sample Preparation}

The buffer solutions ( $\mathrm{pH} 5.5$ and $\mathrm{pH}$ 7.4) were prepared by weighing appropriate amounts of sodium phosphate dibasic and sodium phosphate monobasic salts and made it up to the mark with deionized water in a $1 \mathrm{~L}$ standard volumetric flask. The buffer $\mathrm{pH} 10$ solution was similarly prepared from tris and the borate salt. The solution was then adjusted to the appropriate $\mathrm{pH}$ using $0.1 \mathrm{M} \mathrm{HCl}$ or $0.1 \mathrm{M} \mathrm{NaOH}$. The initial study evaluating the optimum conditions for metal ion remediation for each chelator was performed by spiking 1 gram of kaolinite clay in a nitric acid-prewashed centrifuge tube with $20 \mathrm{ppm}$ of $\mathrm{Cd}$, $\mathrm{Cr}, \mathrm{Cu}, \mathrm{Co}$, and Ni. The spiked kaolinite clay metal ion samples were placed on an orbital shaker for one week to ensure effective binding of heavy metal ions with the kaolinite clay. After one week, $15 \mathrm{~mL}$ of chelator solu- tion was added to the metal ion spiked kaolinite clay mixture and shaken on the orbital shaker for 72 hours to guarantee adequate equilibration and partitioning of metals between the kaolinite and the chelator solution. This was followed by centrifuging the solution at the appropriate centrifuge speed. Once centrifuged, the solution was decanted into a digestion flask. Approximately $5 \mathrm{~mL}$ of $6 \mathrm{M}$ nitric acid was added to the solutions which were then digested for $2 \mathrm{hrs}$ on a hot plate. The nitric acid digested solution was cooled to the room temperature, filtered into a $25 \mathrm{~mL}$ standard volumetric flask, and diluted to the mark with concentrated nitric acid solution.

The solutions were then analyzed for $\mathrm{Cd}, \mathrm{Cr}, \mathrm{Cu}, \mathrm{Co}$, and $\mathrm{Ni}$ metal using an atomic absorption spectrometer (AA-6300, Shimadzu). Each metal analysis was performed in triplicate and the average of the results was reported. All necessary precautions were also observed to ensure the accuracy of the results of this study. First, the 
Table 1. D-optimum experimental design conditions.

\begin{tabular}{cccc}
\hline Experiment \# & $\begin{array}{c}\text { Extracting agent } \\
\text { concentration \% (w/v ) }\end{array}$ & $\mathrm{pH}$ & $\begin{array}{c}\text { Centrifuge } \\
\text { speed (rpm) }\end{array}$ \\
\hline 1 & 0.5 & 10.0 & 4000 \\
2 & 0.1 & 5.5 & 2000 \\
3 & 1.0 & 5.5 & 2000 \\
4 & 0.1 & 10.0 & 2000 \\
5 & 1.0 & 10.0 & 2000 \\
6 & 0.1 & 5.5 & 6000 \\
7 & 1.0 & 5.5 & 6000 \\
8 & 0.1 & 10.0 & 6000 \\
9 & 1.0 & 10.0 & 6000 \\
10 & 0.1 & 5.5 & 4000 \\
11 & 0.1 & 7.4 & 2000 \\
12 & 0.1 & 7.4 & 6000 \\
13 & 0.55 & 5.5 & 2000 \\
14 & 0.55 & 5.5 & 6000 \\
15 & 1.0 & 7.4 & 4000 \\
16 & 0.55 & 7.4 & 2000 \\
\hline
\end{tabular}

highest purity $\mathrm{HNO}_{3}$ acid (purity, 99.999\%) was used for the study. Second, all glassware including the centrifuge test tubes, digestion bottles, and volumetric flasks were pre-soaked in $6 \mathrm{M}$ nitric acid for three days and thoroughly rinsed with deionized water before use to remove impurities and contaminants. Additionally, all metal sample analyses were blank subtracted. The study was also performed in triplicate, and the average of the triplicate analyses was used for the remediation efficiency calculation.

\section{Results and Discussions}

\subsection{Remediation of Heavy Metal Ions}

The optimum experimental conditions where the best metal ion remediation efficiency was achieved for MMs, SDS, and EDTA chelators are shown in Table 2. The overall summary of the result of the metal ions remediation analysis obtained for each chelator at optimum condition is shown in Table 3. The optimum remediation condition of metal ions from kaolinite clay was highly dependent on the type of chelator used, chelator concentration, buffer $\mathrm{pH}$, and on centrifuge speed. SDS has the highest extraction and remediation efficiency at $\mathrm{pH}$ 7.4, at the high centrifuge speed of $6000 \mathrm{rpm}$, and at low SDS concentration $(0.1 \% \mathrm{w} / \mathrm{v})$. The remediation efficiencies of SDS for metal ions ranged between $41.4 \pm 0.4 \%$ for $\mathrm{Cr}$ and $97.0 \pm 0.2 \%$ for $\mathrm{Cu}$. Remediation ability and efficiency of MMs from kaolinite clay was also metal ion and $\mathrm{pH}$ dependent. For instance, high remediation effi-
Table 2. Optimum experiment \# for metal remediation.

\begin{tabular}{cccccc}
\hline \multirow{2}{*}{$\begin{array}{c}\text { Extracting } \\
\text { Agent }\end{array}$} & \multicolumn{5}{c}{ Heavy Metal } \\
\cline { 2 - 6 } & $\mathrm{Cd}$ & $\mathrm{Cr}$ & $\mathrm{Cu}$ & $\mathrm{Co}$ & $\mathrm{Ni}$ \\
\hline Poly-SULV & $(10)$ & $(9)$ & $(10)$ & $(13)$ & $(12)$ \\
Poly-SULA & $(14)$ & $(1)$ & $(2)$ & $(12)$ & $(11)$ \\
Poly-SUG & $(2)$ & $(2)$ & $(7)$ & $(12)$ & $(12)$ \\
SDS & $(12)$ & $(12)$ & $(12)$ & $(7)$ & $(12)$ \\
EDTA & $(12)$ & $(9)$ & $(9)$ & $(4)$ & $(9)$ \\
\hline
\end{tabular}

Table 3. Percentage remediation efficiency of heavy metal at optimum condition.

\begin{tabular}{|c|c|c|c|c|c|}
\hline \multirow{2}{*}{ Chelator } & \multicolumn{5}{|c|}{ Heavy Metal } \\
\hline & $\mathrm{Cd}$ & $\mathrm{Cr}$ & $\mathrm{Cu}$ & Co & $\mathrm{Ni}$ \\
\hline Poly-SULV & $52.6 \pm 0.1$ & $99.9 \pm 8.7$ & $51.3 \pm 0.1$ & $76.9 \pm 0.8$ & $87.3 \pm 0.9$ \\
\hline Poly-SULA & $53.7 \pm 0.2$ & $99.1 \pm 0.7$ & $46.8 \pm 0.1$ & $62.9 \pm 0.1$ & $85.5 \pm 0.3$ \\
\hline Poly-SUG & $51.9 \pm 0.3$ & $62.5 \pm 0.2$ & $38.7 \pm 0.3$ & $58.6 \pm 1.1$ & $184.9 \pm 0.7$ \\
\hline SDS & $57.9 \pm 0.4$ & $41.4 \pm 0.4$ & $97.0 \pm 0.2$ & $55.5 \pm 1.2$ & $279.3 \pm 0.9$ \\
\hline EDTA & $55.3 \pm 0.1$ & $51.6 \pm 0.6$ & $98.6 \pm 0.4$ & $54.7 \pm 1.7$ & $88.9 \pm 0.7$ \\
\hline
\end{tabular}

ciencies were obtained for some MMs at $\mathrm{pH} 5.5$ while better remediation efficiencies were achieved only at $\mathrm{pH}$ 10.0 for some metal ions. However, some MMs demonstrate better metal ion remediation efficiency at physiological $\mathrm{pH}$ 7.4. Molecular micelles therefore demonstrate some degree of metal ion remediation selectivity according to $\mathrm{pH}$. In general, the remediation efficiencies of MMs for metals ranged between $38.7 \pm 0.3 \%$ and $99.9 \pm$ $8.7 \%$. It is of considerable interest to note that SDS can mainly be used for metal ion remediation only at low SDS concentration $(0.1 \% \mathrm{w} / \mathrm{v})$. The observed poor remediation at high SDS concentration was due to poor SDS solubility. In contrast, MMs show high remediation efficiency for some metal ions at low $(0.1 \% \mathrm{w} / \mathrm{v})$, medium $(0.55 \% \mathrm{w} / \mathrm{v})$, or high $(1 \% \mathrm{w} / \mathrm{v})$ concentration. In addition, the typical dynamic equilibrium between SDS micelles in solution significantly hindered the binding of metal ions with SDS, resulting in low remediation efficiency. Unlike SDS, which is a monomeric surfactant, MMs are large polymeric surfactants molecules. Therefore, MMs polymers are inherently more stable than the SDS monomer and tend to have higher binding affinities with metals, ultimately resulting in better remediation efficiency of metal ions from kaolinite clay.

While MMs generally demonstrate better remediation efficiency than SDS, differences in remediation efficiency were also observed among various MMs. In particular, metal ion remediation efficiency obtained for poly-SULV and poly-SULA dipeptide MMs are comparatively better than the remediation efficiency obtained for poly-SUG single peptide MM. The remediation effi- 
ciency obtained for poly-SULV ranged between $51.3 \pm$ $0.1 \%$ and $99.9 \pm 8.7 \%$ while the remediation efficiencies obtained for poly-SULA ranged between $46.8 \pm 0.1 \%$ and $99.1 \pm 0.7 \%$. In contrast, remediation efficiency obtained for poly-SUG ranged between $38.7 \pm 0.3 \%$ and $84.9 \pm 0.7 \%$. Unlike poly-SUG with a single amino acid (glycine) head group, poly-SULV and poly-SULA both contain two amino acid head groups (leucine and valine) and (leucine and alanine), respectively. Differences in the observed remediation efficiencies for dipetide and single amino acid MMs may therefore be associated with the increase in the surface area of the second amino acid head group, increasing the effective number of the binding sites of poly-SULA and poly-SULV with metal ions.

High metal ions remediation efficiency can only be achieved with EDTA as a chelator when using a basic medium $(\mathrm{pH}$ 10.0) and a high centrifuge speed (6000 rpm). Compared with SDS and MMs, EDTA demonstrates better remediation ability for $\mathrm{Cu}$ with $\%$ remediation efficiency of $98.6 \pm 0.4 \%$. However, MMs were found to have comparable remediation ability with ED$\mathrm{TA}$ for $\mathrm{Cd}$ and $\mathrm{Ni}$ ions. Interestingly, MMs remarkably demonstrate superior remediation capability compared with EDTA or SDS for $\mathrm{Cr}$ and $\mathrm{Co}$ ions. For example, poly-SULV and poyly-SULA have $\%$ remediation efficiencies of $99.9 \pm 8.7 \%$ and $99.1 \pm 0.7 \%$, respectively for $\mathrm{Cr}$ ion. These values are significantly higher than the $51.6 \pm 0.6 \%$ remediation efficiency obtained when EDTA was used as the chelator. Similarly, \% remediation efficiencies of $76.9 \pm 0.8 \%$ and $62.9 \pm 0.1 \%$, obtained for Co ion remediation with poly-SULV and poly-SULA, respectively, were significantly larger than the $54.7 \pm 1.7 \%$ remediation efficiency obtained for Co ion when EDTA was used as a chelating agent.

The chemical and structural characteristics of chelators used for the remediation study allows for competitive binding of metal ions from kaolinite clay, ultimately resulting in desorption of metal ions from kaolinite clay. For instance, the SDS surfactant has a sulphate $\left(\mathrm{SO}_{4}^{-2}\right)$ head group which may be used to bind metal ions. The EDTA chelator also potentially has six binding sites, leading to remediation of metal ions from kaolinite clay. The binding of metal ions with MMs chelators could be also achieved and facilitated through direct binding of metal ions with the amino acid polar head groups of MMs. The binding/adsorption mechanism of metals with kaolinite clay is generally believed to involve an ion exchange process and hydrogen bonding formation between the silanol groups on the surface of the kaolinite clay particles [29]. While several factors may influence the extent of adsorption/desorption of metal ions on kaolinite clay, the $\mathrm{pH}$ of the medium, charge/size ratio of the metal ion, hydrolysis of the metal ion, metal ion concen- tration, and chelator concentration are the most prominent factors $[13,14,30,31]$. The extent of desorption or removal of metal ions from kaolinite clay by a chelator is therefore highly dependent on the competitive binding or affinity of the metal ion with kaolinite clay or the chelator. In general, better desorption or removal of metal ion is expected when the affinity between the metal ion and the chelator is stronger than the affinity between the metal ion and kaolinite clay.

\subsection{Partition Coefficient of Heavy Metal Ion Concentration between Kaolinite Clay and Chelators}

The partition coefficient of the metal ion concentration between the kaolinite clay and SDS, EDTA, and MMs chelators of equilibrium were calculated to further the degree of metal ions desorption or transfer from kaolinite clay to the chelators. Table 4 shows the summary of the calculated partition coefficients obtained for each metal ion with various chelators. Once again, the values of the partition coefficients were found to be metal ion and chelator dependent. In general, the partition coefficients of the metal ion concentration between the kaolinite clay /MMs chelators are comparable to the partition coefficient value for clay/SDS chelator or kaolinite clay/ EDTA chelator equilibrium. However, the calculated values of the partition coefficients between the kaolinite clay/Poly-L-SULV and kaolinite clay/Poly-L-SULA chelators for $\mathrm{Cr}$ were considerably larger than the corresponding partition coefficient obtained for other kaolinite clay-chelator equilibria, suggesting stronger affinity of Poly-L-SULV and Poly-L-SULA chelators for Cr ion.

\subsection{Remediation at Different Heavy Metal Ion Concentrations}

To evaluate the influence of metal ion concentrations on the remediation capability of the chelators, further studies were conducted at four different metal ion concentrations. The concentration study was conducted by spiking kaolinite clay with $10 \mathrm{ppm}, 40 \mathrm{ppm}, 60 \mathrm{ppm}$, and $80 \mathrm{ppm}$

Table 4. Partition coefficient of metal ion concentration between kaolinite clay and chelators equilibrium.

\begin{tabular}{cccccc}
\hline \multirow{2}{*}{ Chelator } & \multicolumn{5}{c}{ Heavy Metal } \\
\cline { 2 - 6 } & $\mathrm{Cd}$ & $\mathrm{Cr}$ & $\mathrm{Cu}$ & $\mathrm{Co}$ & $\mathrm{Ni}$ \\
\hline Poly-SULV & 1.11 & 999 & 1.05 & 3.33 & 6.87 \\
Poly-SULA & 1.20 & 110 & 0.90 & 1.74 & 5.90 \\
Poly-SUG & 1.10 & 1.67 & 0.63 & 1.42 & 5.62 \\
SDS & 1.38 & 0.71 & 32.3 & 1.30 & 3.83 \\
EDTA & 1.24 & 1.10 & 70.4 & 1.20 & 8.00 \\
\hline
\end{tabular}


of each metal ion. The remediation procedure and analysis was then performed for each chelator at the optimum condition established in Table $\mathbf{4}$ as reported earlier in the remediation study. In general, the remediation efficiency of each chelator at $10 \mathrm{ppm}, 40,60$, and $80 \mathrm{ppm}$ follow a similar trend obtained for the remediation of metal ions at $20 \mathrm{ppm}$. Interestingly, there was no significant difference between the \% remediation efficiency calculated for chelators at $20 \mathrm{ppm}$ compared to other concentrations. Insignificant differences in \% remediation efficiencies of metal ions observed for the chelators were due to the effectiveness of D-optimum experimental design for the optimization of experimental conditions to achieve a global optimum remediation condition. The optimum condition established at $20 \mathrm{ppm}$ of metal ions can therefore be used for efficient remediation of metal ions over a wider range of concentration.

\section{Conclusion}

In conclusion, the potential utility of molecular micelles as chelators for metal ion remediation from kaolinite clay was investigated using the D-optimum experimental design strategy. In general, the remediation efficiency of chelators was found to be dependent on the type of chelator used for the remediation and the chelator concentration. In addition, the experimental conditions including buffer $\mathrm{pH}$, and centrifuge speed were observed to significantly influence the remediation ability of the chelator from kaolinite clay. In general, the result of the study indicated that molecular micelles have better metal ion remediation efficiency than the SDS surfactant and have comparable remediation ability with EDTA for most metal ions. However, compared with SDS and EDTA, MMs notably demonstrated better remediation efficiencies for $\mathrm{Cr}$ and $\mathrm{Cu}$ ions. Furthermore, the use of D-optimum experimental design employed for the optimization of experimental remediation conditions in this study is advantageous, allowing for the establishment of global optimum metal ion remediation conditions for chelators with fewer experiments, reducing the cost and time of analysis. Overall, the use of molecular micelles as potential chelators for metal ion remediation is promising. Considering several advantages of molecular micelles, with further development and more study, MMs can potentially be used as alternative chelators for metal ion remediation in various analytical and environmental studies.

\section{Acknowledgements}

The authors acknowledge the financial support from NSF-RIA Grant \# HRD-1137453 of this study. We are also thankful to Dr. Isiah M. Warner, Chemistry Depart- ment, Louisiana State University for the provision of molecular micelles chelators used for the heavy metal remediation

\section{REFERENCES}

[1] G. U. Adie and O. Osibanjo, "Accumulation of Lead and Cadmium by Four Tropical Forage Weeds Found in the Premises of an Automobile Battery Manufacturing Company in Nigeria," Toxicology and Environmental Chemistry, Vol. 92, No. 1, 2010, pp. 39-49. doi:10.1080/02772240902918337

[2] S. O. Fakayode and B. I.Olu-Owolabi, "Heavy Metal Contamination of Roadside Topsoil in Osogbo, Nigeria: Its Relationship to Traffic Density and Proximity to Highways," Environmental Geology, Vol. 44, No. 2, 2003, pp. 150-157.

[3] S. O. Fakayode and P. C. Onianwa, "Heavy Metal Contamination of Soil, and Bioaccumulation in Guinea Grass (Panicum maximum) around Ikeja Industrial Estate, Lagos, Nigeria," Environmental Geology, Vol. 43, No. 1-2, 2002, pp. 145-150. doi:10.1007/s00254-002-0633-9

[4] S. Fontana, M. Wahsha and C. Bini, "Preliminary Observations on Heavy Metal Contamination in Soils and Plants of an Abandoned Mine in Imperina Valley (Italy)," Agrochimica, Vol. 54, No. 4, 2010, pp. 218-231.

[5] Z. Yang, W. Lu, Y. Long, X. Bao and Q. Yang, "Assessment of Heavy Metals Contamination in Urban Topsoil from Changchun City, China," Journal of Geochemical Exploration, Vol. 108, No. 1, 2011, pp. 27-38. doi:10.1016/j.gexplo.2010.09.006

[6] O. J. Okunola, A. Uzairu, G. I. Ndukwe and S. G. Adewusi, "Assessment of $\mathrm{Cd}$ and $\mathrm{Zn}$ in Roadside Surface Soils and Vegetations along Some Roads of Kaduna Metropolis, Nigeria," Journal of Environmental Science, Vol. 2, No. 4, 2008, pp. 266-274.

[7] Agency for Toxic Substances and Diseases Registry (ASTDR), "Toxicological Profile for Lead," US Department of Health and Human Services, Public Health Services, 2009.

http://www.atsdr.cdc.gov/toxprofiles/tp13.pdf

[8] S. Tong, Y. E. von Schirnding and T. Prapamontol, "Environmental, Lead Exposure: A Public Health Problem of Global Dimensions," Bulletin of World Health Organization, Vol. 78, No. 9, 2000, pp. 1068-1077.

[9] W. Chen, L. Hsiao and K. K. Chen, "Metal Desorption from Copper(II)/Nickel(II)-Spiked Kaolin as a Soil Component Using Plant-derived Saponin Biosurfactant," Process Biochemistry, Vol. 43, No. 5, 2008, pp. 488-498. doi:10.1016/j.procbio.2007.11.017

[10] M. W. Amer, F. I. Khalili and A. M. Awwad, “Adsorption of Lead, Zinc and Cadmium Ions on PolyphosphateModified Kaolinite Clay," Journal of Environmental Chemistry and Ecotoxicology, Vol. 2, No. 1, 2010, pp. 1-8.

[11] B. I. Olu-Owolabi and E. I. Unuabonah, "Adsorption of $\mathrm{Zn}^{2+}$ and $\mathrm{Cu}^{2+}$ onto Sulphate and Phosphate-Modified Bentonite," Applied Clay Science, Vol. 51, No. 1-2, 2011, 
pp 170-173. doi:10.1016/j.clay.2010.10.022

[12] E. I. Unuabonah, B. I. Olu-Owolabi, K. O. Adebowale and L. Z. Yang, "Removal of Lead and Cadmium Ions from Aqueous Solution by Polyvinyl Alcohol-Modified Kaolinite Clay: A Novel Nano-Clay Adsorbent," Adsorption Science and Technology, Vol. 26, No. 6, 2008, pp. 383-405. doi:10.1260/0263-6174.26.6.383

[13] W. Omar and H. Al-Itawi, "Removal of $\mathrm{Pb}^{+2}$ Ions from Aqueous Solutions by Adsorption on Kaolinite Clay," American Journal of Applied Sciences, Vol. 4, No. 7, 2007, pp 502-507. doi:10.3844/ajassp.2007.502.507

[14] E. Repo, L. Malinen, R. Koivula, R. Harjula and M. Sillanpää, "Capture of $\mathrm{Co}(\mathrm{II})$ from Its Aqueous EDTAChelate by DTPA-Modified Silica Gel and Chitosan," Journal of Hardzadous Material, Vol. 187, No. 1-3, 2011, pp. 122-132. doi:10.1016/j.jhazmat.2010.12.113

[15] C. M. Zvinowanda, J. O. Okonkwo, P. N. Shabalala and N. M. Agyei, "A Novel Adsorbent for Heavy Metal Remediation in Aqueous Environments," International Journal of Environmental Science and Technology, Vol. 6, No. 3, 2009, pp. 425-434.

[16] S. Ahmady-Asbchin, Y. Andres, C. Gerente, P. Le Cloirec, "Natural Seaweed Waste as Sorbent for Heavy Metal Removal from Solution," Environmental Technology, Vol. 30, No. 7, 2009, pp. 755-762. doi:10.1080/09593330902919401

[17] S. S. Ahluwalia and D. Goyal, "Microbial and Plant Derived Biomass for Removal of Heavy Metals from Wastewater," Bioresource Technology, Vol. 98, No. 12, 2007, pp. 2243-2257. doi:10.1016/j.biortech.2005.12.006

[18] A. Atkinson, A. Donev and R. Tobias, "Optimum Experimental Designs, with SAS (Oxford Statistical Science Series)," Oxford University Press Inc., New York, 2007,

[19] R. K. Prasad, R. R. Kumar and S. N. Srivastava, "Design of Optimum Response Surface Experiments for Electro-Coagulation of Distillery Spent Wash," Water, Air, Soil Pollution, Vol. 191, No. 1-4, 2008, pp. 5-13. doi:10.1007/s11270-007-9603-x

[20] Z. Gong, M. Zhang, A. S. Mujumdar and J. Sun, "Spray Drying and Agglomeration of Instant Bayberry Powder," Drying Technology, Vol. 26, No. 1, 2008, pp. 116-121. doi:10.1080/07373930701781751

[21] L. B. Dantas, H. R. B. Orlande and R. M. Cotta, "Estimation of Dimensionless Parameters of Luikov's System for Heat and Mass Transfer in Capillary Porous Media," International Journal of Thermal Sciences, Vol. 41, No. 3, 2002, pp. 217-227. doi:10.1016/S1290-0729(01)01310-2

[22] A. A. Williams, S. O. Fakayode, X. Huang and I. M. Warner, "Use of Multivariate Analysis for Optimization of Separation Parameters and Prediction of Migration
Time, Resolution and Resolution per Unit Time in Micellar Electrokinetic Chromatography," Electrophoresis, Vol. 27, No. 21, 2006, pp. 4127-4140. doi:10.1002/elps.200600071

[23] C. A. Luces, S. O. Fakayode, M. Lowry and I. M. Warner, "Protein Separations Using Experimental Design for Optimization of Separation Parameters with Polyelectrolyte Multilayer Coatings," Electrophoresis, Vol. 29, No. 4, 2008, pp. 889-900. doi:10.1002/elps.200700634

[24] G. M. Ganea, C. M. Sabliov, A. O. Ishola, S. O. Fakayode and I. M. Warner, "Experimental Design and Multivariate Analysis for Optimizing Poly (D,L-Lactide-co-Glycolide) (PLGA) Nanoparticle Synthesis Using Molecular Micelles," Journal of Nanoscience and Nanotechnology, Vol. 8, No. 1, 2008, pp. 280-292.

[25] O. Anurukvorakun, W. Suntornsuk and L. Suntornsuk, "Factorial Design Applied to a Non-Aqueous Capillary Electrophoresis Method for the Separation of $\beta$-Agonists," Journal of Chromatography A, Vol. 1134, No. 1-2, 2006, pp. 326-332. doi:10.1016/j.chroma.2006.09.021

[26] N. De la Cruz-Landero, V. E. Hernandez, E. Guevara, M. A. Lopez-Lopez, A. T. Santos, E. Ojeda-Trejo, A. Alderete-Chavez and A. Lupinus, "Versicolor Response in Soils Contaminated with Heavy Metals from a Petroleum Extraction Field," Journal of Applied Science, Vol. 10, No. 8, 2010, pp. 694-698. doi:10.3923/jas.2010.694.698

[27] J. Wang and I. M. Warner, "Chiral Separations Using Micellar Electrokinetic Capillary Chromatography and a Polymerized Chiral Micelle," Analytical Chemistry, Vol. 66, No. 21, 1994, pp. 3773-3776. doi: $10.1021 / \mathrm{ac} 00093 \mathrm{a} 037$

[28] F. H. Billiot, E. J. Billiot and I. M. Warner, "Comparison of Monomeric and Polymeric Amino Acid Based Surfactants for Chiral Separations," Journal of Chromatography A, Vol. 922, No. 1-2, 2001, pp. 329-338. doi:10.1016/S0021-9673(01)00865-2

[29] A. Dube, R. Zbytniewski, T. Kowalkowski, E. Cukrowska and B. Buszewski, "Adsorption and Migration of Heavy Metals in Soil," Polish Journal of Environmental Studies, Vol. 10, No. 1, 2001, pp. 1-10.

[30] P. Srivastava, B. Singh and M. J. Angove, "Competitive Adsorption of C(II) onto Kaolinite as Affected by $\mathrm{pH}$," 3rd Australian New Zealand Soils Conference, Sydney, 5-9 December 2004, pp. 5-9.

[31] V. Chantawong, N. W. Harvey and V. N. Bashkin, "Comparison of Heavy Metal Adsorptions by Thai Kaolin and Ballclay," Water, Air, Soil Pollution, Vol. 148, No. 1-4, 2003, pp. 111-125. doi:10.1023/A:1025401927023 